\title{
Morphology and Timing of Spawning of Umatilla Dace (Rhinichthys umatilla) in the Slocan River, British Columbia
}

\author{
LOUISE PORTO ${ }^{1,2}$ and CRYSTAL LAWRENCE ${ }^{1}$ \\ ${ }^{1}$ Amec Foster Wheeler Environment and Infrastructure, Suite 601E, 601 Front Street, Nelson, British Columbia V1L 4B6 Canada \\ ${ }^{2}$ Corresponding author: louise.porto@amecfw.com
}

Porto, Louise, and Crystal Lawrence. 2016. Morphology and timing of spawning of Umatilla Dace (Rhinichthys umatilla) in the Slocan River, British Columbia. Canadian Field-Naturalist 130(3): 224-230.

Umatilla Dace (Rhinichthys umatilla, Cyprinidae) are endemic to the Columbia River Basin. In Canada, this species is assessed as "threatened". Little is known about its life history, especially with respect to spawning in the wild. A total of 688 specimens were captured, including 39 mature males and females displaying spawning colouration and tubercles, during minnow trapping and electrofishing surveys conducted on the Slocan River in southern British Columbia, Canada. Fertilized eggs were not observed, but eggs and milt were expressed from ripe individuals. Spawning was estimated to occur from mid-July to mid-September. Aquatic macrophytes and flooded terrestrial vegetation were important habitat features for mature Umatilla Dace leading up to the spawning period on the Slocan River. To our knowledge this is the first time that Umatilla Dace have been captured in spawning condition and observed with spawning colouration and tubercles in the wild in Canada. Results of this study will aid the development of recovery plans and management for this species in British Columbia.

Key Words: Umatilla Dace; Rhinichthys umatilla; spawning morphology; spawning time; Slocan River; Species at Risk Act; special concern; threatened status

\section{Introduction}

Few studies have reported on dace spawning in the wild or under laboratory conditions, and those that exist have focused on widespread species, such as Longnose Dace (Rhinichthys cataractae; e.g., McPhail 2007), Western Blacknose Dace (Rhinichthys obtusus; Gibbons and Gee 1972), and Speckled Dace (Rhinichthys osculus; e.g., Kaya 1991).

In Canada, Umatilla Dace (Rhinichthys umatilla) are listed federally under the Species At Risk Act as "special concern" (SARA Registry 2016) although they were reassessed by the Committee on the Status of Endangered Wildlife in Canada in 2010 as "threatened" (COSEWIC 2010). Reasons for its designation as "threatened" included a limited distribution within a habitat extensively modified by hydroelectric development, climate change, water extraction, and aquatic invasive species. They are endemic to the Columbia River Basin and are thought to have habitat and spawning requirements similar to those of the more common Longnose Dace (Harvey and Brown 2011). However, in Canada, Umatilla Dace are present only in British Columbia and little is known about their life history, especially with respect to reproductive biology (Peden and Hughes 1988; Haas 2001; McPhail 2007; Harvey and Brown 2011; Dr. Brian Sidlauskas, personal communication). Previous studies in the Canadian Columbia Basin have reported Umatilla Dace from the lower portion of the Columbia River as well as in the Slocan
River (McPhail 2007). As for many dace species, Umatilla Dace are sexually mature at age two years and spawning occurs in summer (Haas 2001; McPhail 2007). However, eggs have not been located in the wild and adult spawning characteristics within a natural setting have not been described.

General habitat use by Umatilla Dace has been examined. Adults are found in areas with large boulders, at depths greater than $1 \mathrm{~m}$ and bottom water velocities of $0.05 \mathrm{~m} / \mathrm{s}$ (Peden and Orchard 1993; McPhail 2007). Juveniles are typically found in nearshore, shallow areas (10-70 cm deep) over large gravel or boulder substrates (McPhail 2007). The Umatilla Dace's spotty distribution, low abundance, and range fragmentation (by hydroelectric dams) make some populations vulnerable (McPhail 2007).

The objective of this study was to describe spawning morphology and timing of Umatilla Dace in a wild population within an unregulated river system. Information reported here was part of a larger study with multiple objectives conducted for BC Hydro (AMEC Environment \& Infrastructure 2014) and may help conservation efforts to prevent extirpation of this species from the Canadian portion of the Columbia River Basin.

\section{Study Area}

The Slocan River in the southeast interior of British Columbia drains Slocan Lake and flows approximately $65 \mathrm{~km}$ south to join the lower Kootenay River (Figure 
1). The Slocan River study area (AMEC Environment \& Infrastructure 2014) encompassed approximately $44 \mathrm{~km}$ of river length from north of Winlaw to the confluence of the lower Kootenay River. Inflows to the study area are from tributaries, most notably the Little Slocan River. The Slocan River follows a sinuous pattern with peak freshet occurring in May or June and annual low flow through the fall and winter.

\section{Methods}

Sample sites and timing

Sites sampled on the Slocan River were approximately $100 \mathrm{~m}$ in length and varied in width depending on seasonal flows. Sampling was conducted over three years (2011-2013), with timing focused on the projected spawning and larval rearing period for Umatilla Dace (biweekly: July through September; McPhail 2007).

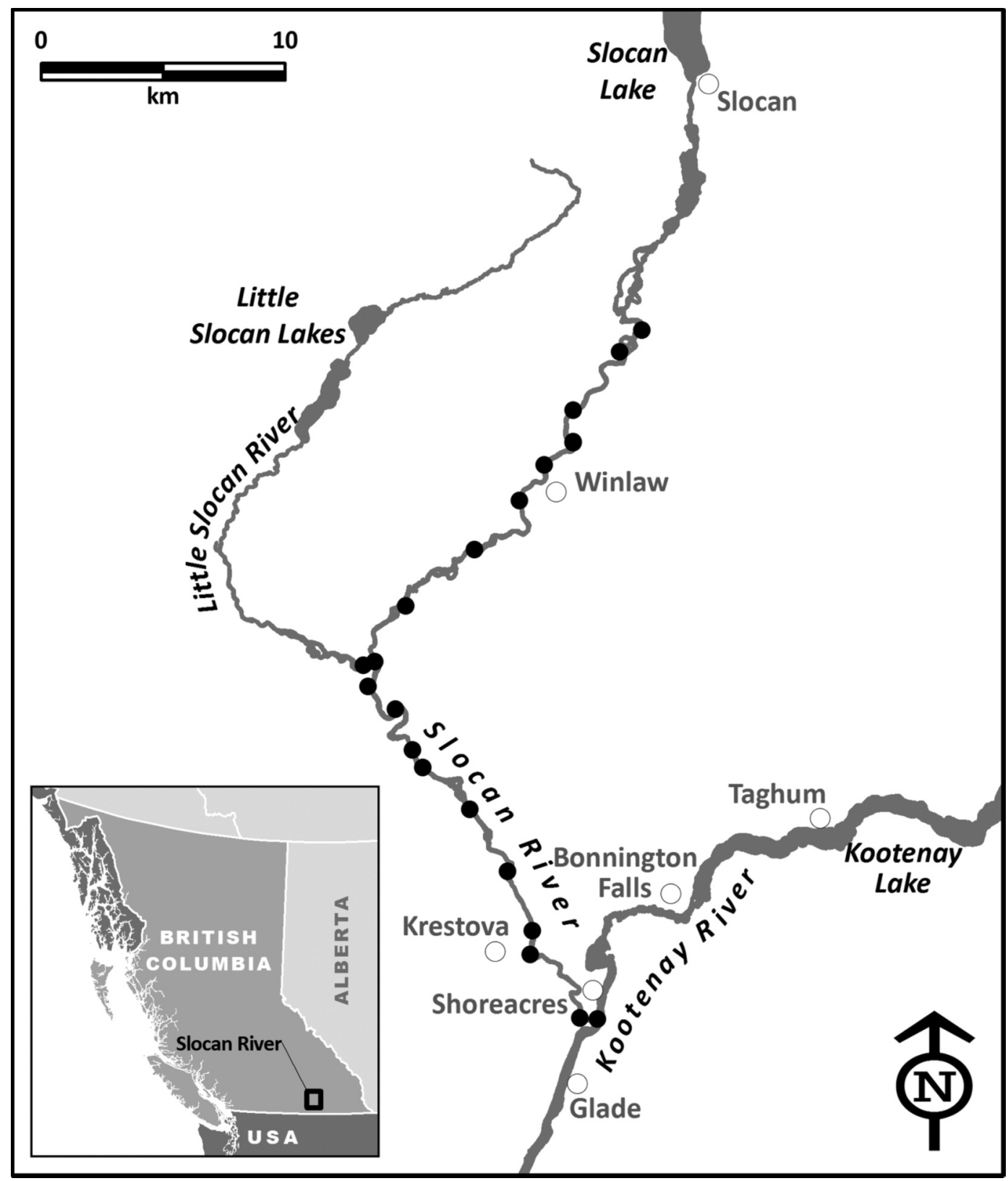

FIGURE 1. Overview of the Slocan River showing Umatilla Dace (Rhinichthys umatilla) sampling locations (black dots). 


\section{Capture methods}

Sites were sampled repeatedly using a combination of backpack electrofishing and minnow trapping techniques (Murphy and Willis 1996). A total of $15.3 \mathrm{~h}$ of single-pass electrofishing was carried out in nearshore habitat at depths $<1.5 \mathrm{~m}$ and water velocities $<1.5 \mathrm{~m} / \mathrm{s}$. We also carried out $11553 \mathrm{~h}$ of minnow trapping using Gee-40 (Tackle Factory, Fillmore, NY, USA) galvanized minnow traps (42 $\mathrm{cm}$ long and $19.5 \mathrm{~cm}$ diameter) baited with salmon roe wrapped in aluminium foil. Traps were set overnight for $16-24 \mathrm{~h}$ at depths of $0.1-$ $5 \mathrm{~m}$ and water velocity $<1.0 \mathrm{~m} / \mathrm{s}$. The minimum girth of fish captured by minnow trap was limited by mesh size $(0.64 \mathrm{~cm})$ and the maximum girth was limited by the trap entrance $(2.54 \mathrm{~cm})$. Captured fish were identified, measured (fork length in $\mathrm{mm}$ ), and inspected for sexual maturity.

\section{Life stage and maturity}

Captured Umatilla Dace were assigned a life stage (adult $>45 \mathrm{~mm}$; juvenile 35-45 mm; young-of-theyear $<35 \mathrm{~mm}$ ) based on life history characteristics (Haas 2001; McPhail 2007; Keeler et al. 2010; AMEC Environment \& Infrastructure 2014). Maturity stage was also assigned to adults (Ricker 1971; McPhail 2007). Sexually mature adults displayed external characteristics including tubercles on their dorsal surface, colouration, and/or extrusion of gametes. Extruded eggs were qualitatively evaluated (for colour and size), with average egg diameter (to the nearest millimetre) recorded for four individuals.

\section{Habitat use and environmental variables}

Habitat measurements were taken at the point of fish capture: water depth (m), average column water velocity $(\mathrm{m} / \mathrm{s})$ taken at $60 \%$ depth, substrate type, percentage of substrate embedded within other substrates, as well as type and presence of vegetation (i.e., aquatic macrophytes, flooded terrestrial vegetation, woody debris). Substrate categories included silt $(<0.6 \mathrm{~mm})$, sand $(0.6-4 \mathrm{~mm})$, gravel $(>4-64 \mathrm{~mm})$, cobble $(>64-256 \mathrm{~mm})$, or boulder $(>256 \mathrm{~mm})$. Slocan River discharge records were obtained from the Water Survey of Canada gauge near Crescent Valley (station no. 08NJ013) and water temperature was collected at one index site by Hobo Tidbit v2 loggers (accuracy $\pm 0.2^{\circ} \mathrm{C}$; Onset, Bourne, Massachusetts, USA), set to record water temperature every hour.

\section{Spawning time}

Spawning time was estimated based on the capture of sexually mature adults and the back-calculation of incubation times from the capture of young-of-the-year Umatilla Dace (Haas 2001; McPhail 2007). The incubation period for Umatilla Dace is $5-7$ days at $18^{\circ} \mathrm{C}$ and eggs hatch over a two-day period (Haas 2001). Fry are $7 \mathrm{~mm}$ long at hatching, and emerge from the egg stage approximately one week later at $10 \mathrm{~mm}$ (McPhail 2007).

\section{Results}

In total, 688 Umatilla Dace were captured during this study, including 39 that were classified as mature. Other captured species are listed in Table 1.

\section{Spawning observations}

A total of 39 mature Umatilla Dace were captured by minnow trapping $(n=38)$ and backpack electrofishing $(n=1)$ in the Slocan River during this study (Table 2). Of these, nine were classified as male and six as female based on the expression of gametes (Table 2). Two other adults were classified as females based on swollen urogenital pores (see below). The remaining 22 fish were of unknown sex, but had external features suggesting that they may spawn or had spawned that season (Table 2).

Ripe males that expressed milt had orange colour on their lips and/or operculum as well as on their pectoral, pelvic, and/or anal fins and fin insertions (Figure 2). In addition to these traits, two mature males, captured 13 June and 9 July 2013, also had tubercles on scales above the lateral line.

TABLE 1. Total number of fish captured by species in the Slocan River, British Columbia, 2011-2013.

\begin{tabular}{llc}
\hline \hline Common name & Scientific name & No. caught \\
\hline Redside Shiner & Richardsonius balteatus & 1306 \\
Longnose Dace & Rhinichthys cataractae & 832 \\
Northern Pikeminnow & Ptychocheilus oregonensis & 722 \\
Torrent Sculpin & Cottus rhotheus & 723 \\
Umatilla Dace & Rhinichthys umatilla & 688 \\
Sculpin & Cottus sp. & 491 \\
Shorthead Sculpin & Cottus confusus & 460 \\
Sucker & Catostomus sp. & 345 \\
Rainbow Trout & Oncorhynchus mykiss & 137 \\
Prickly Sculpin & Cottus asper & 53 \\
Columbia Sculpin & Cottus hubbsi & 28 \\
Mountain Whitefish & Prosopium williamsoni & 11 \\
Dace & Rhinichthys sp. & 7 \\
\hline \hline
\end{tabular}


TABLE 2. Fork length (mm) of mature male and female Umatilla Dace (Rhinichthys umatilla) captured in the Slocan River, British Columbia, 2011-2013.

\begin{tabular}{lcll}
\hline \hline & & \multicolumn{2}{c}{ Fork length $(\mathrm{mm})$} \\
\cline { 3 - 4 } Sex & $\begin{array}{c}\text { Sample } \\
\text { size }\end{array}$ & $\begin{array}{l}\text { Mean } \\
\pm \text { SD }\end{array}$ & Range \\
\hline Female & 8 & $95 \pm 7$ & $87-110$ \\
Male & 9 & $82 \pm 9$ & $70-93$ \\
Unknown & 22 & $77 \pm 11$ & $55-96$ \\
Total & 39 & $82 \pm 12$ & $55-110$ \\
\hline \hline
\end{tabular}

Note: $\mathrm{SD}=$ standard deviation.

External characteristics of ripe females expressing eggs included red colouration on lips and pelvic and pectoral fin insertions (Figure 2). One of these females also had tubercles on scales above the lateral line. However, one female, captured on 17 July 2013, did not have tubercles or display any red colouration, but expressed three eggs that were opaque white and $1 \mathrm{~mm}$ in diameter. One female displaying red pigment on the upper lip had eggs that were either opaque and $1 \mathrm{~mm}$ in diameter or yellow and $1.3-1.5 \mathrm{~mm}$ in diameter. A spent female, captured on 12 August 2013, displayed tubercles on scales above the lateral line and red colour on

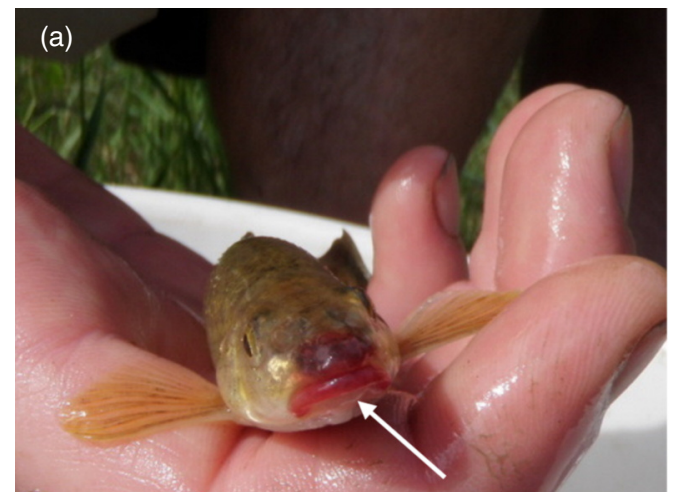

the snout; this fish had a soft, hollow abdomen and expressed only two eggs (non-described), suggesting spawning was complete. Two females, captured on 7 September 2011 and 13 August 2013, had slight red colouration on their lips and did not express eggs, but had flaccid abdomens and swollen urogenital pores and were likely spent. Fertilized eggs were not observed during this study.

Unidentified young-of-the-year dace were observed in the Slocan River in early August, but their small size ( $<18 \mathrm{~mm}$ fork length) confounded identification to the species level. Confirmed young-of-the-year Umatilla Dace were observed beginning in September through October during all three study years.

\section{Spawning habitat}

Mature Umatilla Dace were captured at depths of $0.2-1.5 \mathrm{~m}$ and average column velocities of $0-0.3 \mathrm{~m} / \mathrm{s}$ over silt substrates associated with aquatic macrophytes and flooded terrestrial vegetation and, to a lesser degree, over silt and cobble substrates without vegetation (Table 3). Males were not captured at sites with flooded vegetation, whereas females were equally captured at sites with flooded vegetation and with aquatic macrophytes (Table 3).

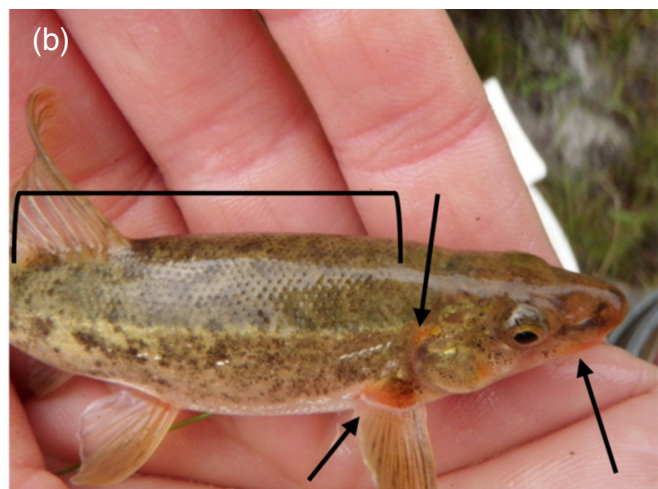

FIGURE 2. Sexually mature Umatilla Dace (Rhinichthys umatilla) observed on the Slocan River, British Columbia. Female (a) with red pigment on lips and snout (white arrow) observed on 9 August 2011 and male (b) with orange pigment on lips, pectoral fin insertions, operculum (black arrows), and tubercles (black bracket) on dorsal surface observed on 14 June 2013. Photos: L. Porto.

TABLE 3. Habitat characteristics at minnow trap locations* where mature Umatilla Dace (Rhinichthys umatilla) were captured in the Slocan River, British Columbia, 2011-2013.

\begin{tabular}{|c|c|c|c|c|c|c|c|c|c|}
\hline \multirow[b]{2}{*}{ Sex } & \multirow[b]{2}{*}{$\begin{array}{c}\text { Sample } \\
\text { size }\end{array}$} & \multicolumn{2}{|c|}{ Water depth (m) } & \multicolumn{2}{|c|}{ Water velocity $(\mathrm{m} / \mathrm{s})$} & \multicolumn{4}{|c|}{ Substrate composition ( $\%$ of total) } \\
\hline & & $\begin{array}{c}\text { Mean } \\
\pm \\
\text { SD }\end{array}$ & Range & $\begin{array}{c}\text { Mean } \\
\pm \\
\text { SD }\end{array}$ & Range & $\begin{array}{c}\text { Aquatic } \\
\text { macrophytes }\end{array}$ & $\begin{array}{c}\text { Flooded } \\
\text { terrestrial } \\
\text { vegetation }\end{array}$ & Silt & Cobble \\
\hline Female & 8 & $0.7 \pm 0.3$ & $0.3-1.0$ & $0.07 \pm 0.12$ & $0.0-0.3$ & 38 & 38 & 12 & 12 \\
\hline Male & 9 & $0.6 \pm 0.3$ & $0.2-1.2$ & $0.03 \pm 0.07$ & $0.0-0.2$ & 67 & 0 & 33 & 0 \\
\hline Unknown & 21 & $1.0 \pm 0.4$ & $0.2-1.5$ & $0.01 \pm 0.02$ & $0.0-0.1$ & 43 & 38 & 19 & 0 \\
\hline Total & 38 & $0.8 \pm 0.4$ & $0.2-1.5$ & $0.02 \pm 0.07$ & $0.0-0.3$ & 29 & 47 & 21 & 3 \\
\hline
\end{tabular}

Note: $\mathrm{SD}=$ standard deviation.

* Habitat data were not recorded for the single mature Umatilla Dace captured by electrofishing. 
Spawning time

The estimated spawning period for Umatilla Dace extends from early July to mid-September when water temperatures are between $10^{\circ} \mathrm{C}$ and $21^{\circ} \mathrm{C}$ soon after peak freshet on the Slocan River (Figure 3). Peak spawning may occur between $16^{\circ} \mathrm{C}$ and $21^{\circ} \mathrm{C}$ based on the presence of ripe fish.
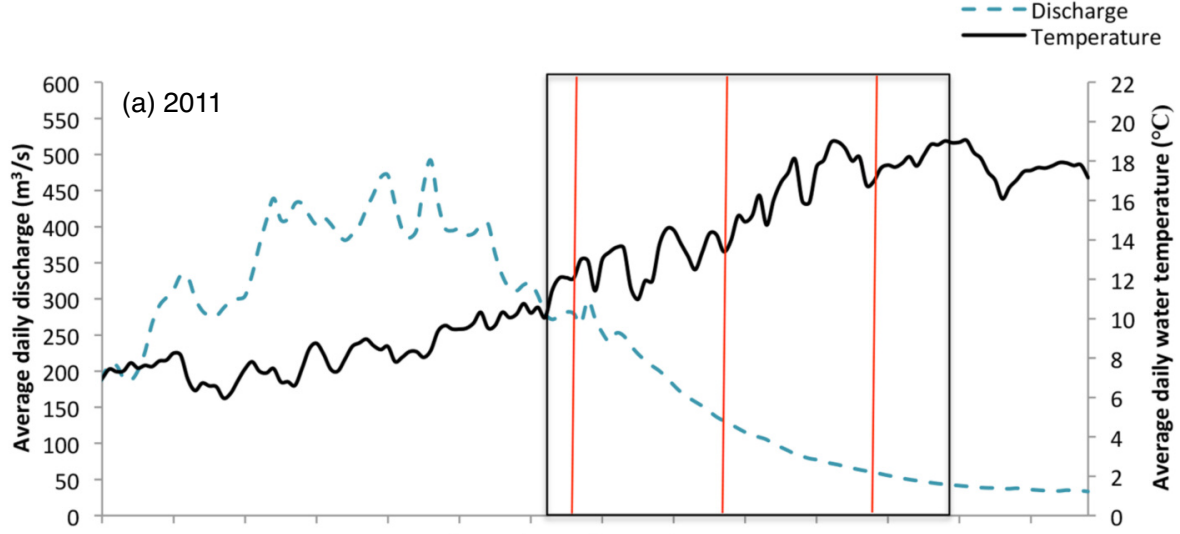

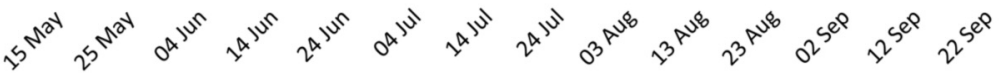

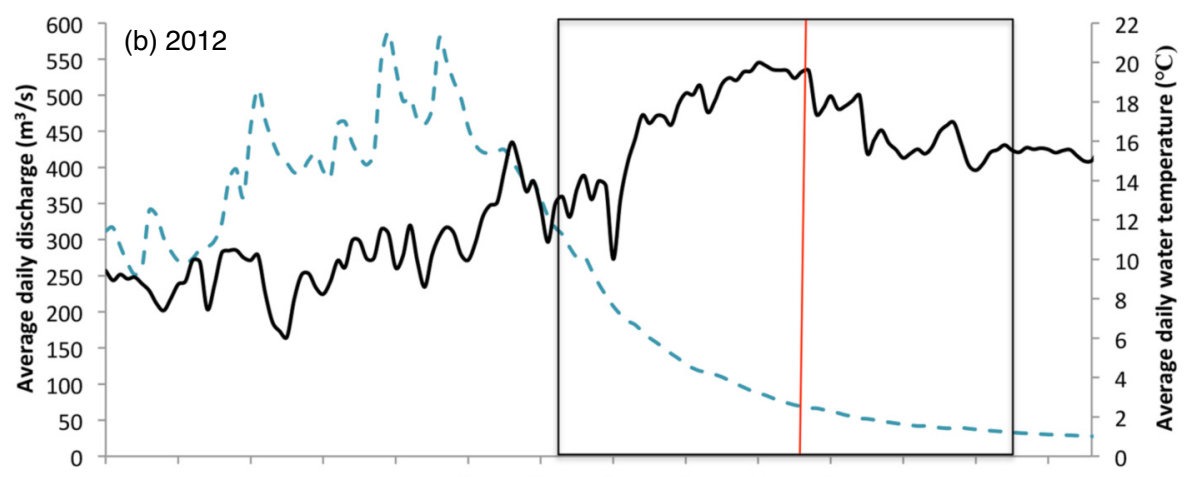

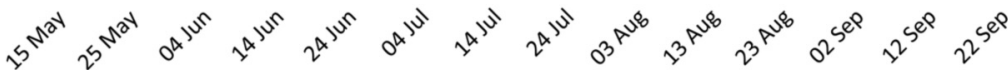

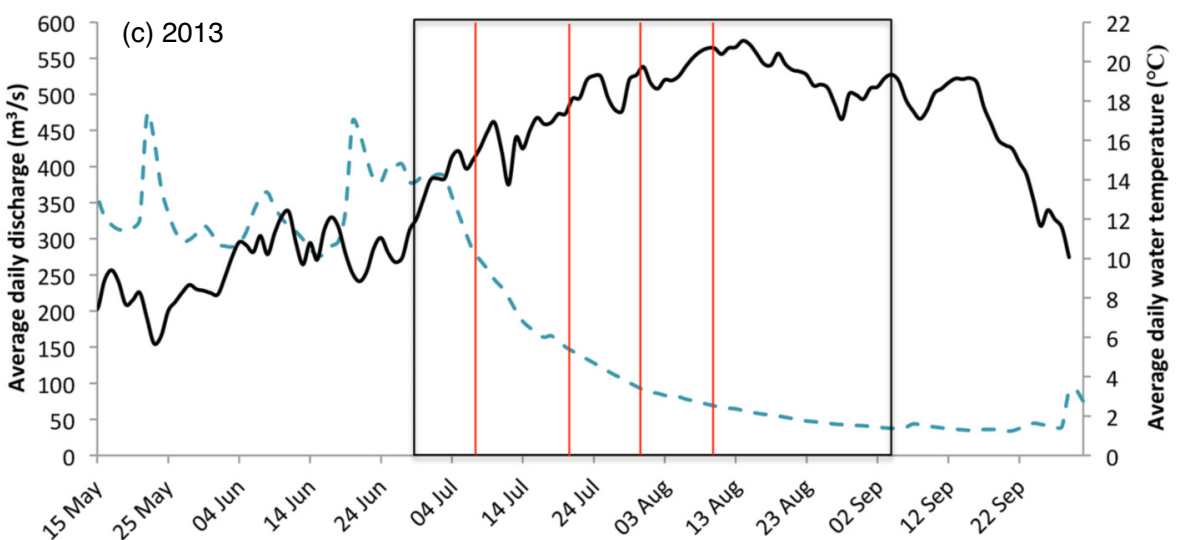

FIGURE 3. Discharge volume, water temperature, and estimated spawning period (boxes) for Umatilla Dace (Rhinichthys umatilla) in the Slocan River, British Columbia, in (a) 2011, (b) 2012, and (c) 2013. Red vertical lines within the boxes represent dates when ripe individuals were collected. 


\section{Discussion}

To our knowledge, this is the first time that the Umatilla Dace has been captured in spawning condition and observed with spawning colouration and tubercles in the wild in Canada (D. McPhail, personal communication). Males in spawning condition displayed orange pigmentation on their lips and/or operculum as well as on their pelvic, pectoral, and/or anal fin insertions, and many expressed milt when slight pressure was applied to their abdomen. Females in spawning condition displayed bright red colouration on their lips, snout, pectoral, and/or pelvic fin insertions, and some females with these characteristics also expressed eggs. Spawning tubercles were observed on mature males $(22 \%)$ and females (25\%). Development of dorsal tubercles and red-orange colouration observed on mature Umatilla Dace are not uncommon features for dace species in spawning condition (i.e., Longnose Dace; McPhail 2007), but these characteristics have not been previously reported for Umatilla Dace (McPhail 2007).

Although we did not directly observe spawning or find fertilized eggs, spawning likely begins soon after peak freshet over the period of annual maximum water temperature based on the presence of ripe individuals. On the Slocan River, ripe Umatilla Dace were captured at water temperatures between $16^{\circ} \mathrm{C}$ and $21^{\circ} \mathrm{C}$ from mid-July to late August. This confirms that Umatilla Dace spawn in mid-summer because near-ripe individuals were collected in July, and the closely related Leopard Dace (Rhinichthys falcatus) and Speckled Dace species also spawn at this time (Peden and Hughes 1981, 1984; Peden 1991; McPhail 2007). Direct spawning observations for Umatilla Dace have been made only under laboratory conditions, but detailed spawning behaviour and external characteristics were not documented (Haas 2001).

Baited minnow traps were the best method to capture Umatilla Dace during the spring/summer period (AMEC Environment \& Infrastructure 2014), and it is likely that mature Umatilla Dace were artificially attracted to the minnow traps set close to spawning locations. Whether these fish were drawn into the baited traps to feed, seek shelter, or spawn remains unknown at this time.

Information obtained during this study has added to our knowledge of the life history of the Umatilla Dace, a species that is often misidentified and assumed to be similar to the more common Longnose Dace (Harvey and Brown 2011). This new information on spawning time will aid in recovery plans and management of this species in other, more regulated portions of the Columbia River Basin in British Columbia.

\section{Acknowledgements}

Financial and scientific support for this research came from BC Hydro Power Authority, Water Licensing Requirements Division (CLBMON-43 Lower Co- lumbia River Sculpin and Dace Life History Assessment). Dr. Don McPhail (University of British Columbia) provided taxonomic guidance. Dr. Brian Sidlauskas of the Fisheries \& Wildlife Department, Oregon State University, confirmed information on life history and reproductive biology. Field assistance was provided by fisheries technicians from the Canadian Columbia Inter-tribal Fisheries Commission (Cranbrook, British Columbia), the Ministry of Environment and Forest, Lands and Natural Resource Operations (Nelson, British Columbia), Clint Tarala, Jimmy Robbins, and Katy Fraser. Rachel Keeler (Amec Foster Wheeler Environment and Infrastructure) and Guy Martel (BC Hydro) provided review comments that helped improve this article. The manuscript was also greatly improved by comments from two anonymous reviewers.

\section{Literature Cited}

AMEC Environment \& Infrastructure. 2014. Lower Columbia River sculpin and dace life history assessment (CLBMON-43): year 5 technical report (2013). AMEC, Nelson, British Columbia, Canada. Accessed 7 December 2015. http://tinyurl.com/z9cpgle.

COSEWIC (Committee on the Status of Endangered Wildlife in Canada). 2010. COSEWIC assessment and status report on the Umatilla Dace Rhinichthys umatilla in Canada. COSEWIC, Environment Canada, Gatineau, Quebec, Canada. Accessed 2 September 2016. http:// http://sara registry.gc.ca/virtual_sara/files/cosewic/sr\%5FUmatilla $\%$ 20 Dace $\% 5$ F $0810 \% 5$ Fe.pdf.

Gibbons, J. R. H., and J. H. Gee. 1972. Ecological segregation between Longnose and Blacknose Dace (genus Rhinichthys) in the Mink River, Manitoba. Journal of the Fisheries Board of Canada 29: 1245-1252.

Haas, G. R. 2001. The evolution through natural hybridizations of the Umatilla dace (Pisces: Rhinichthys umatilla), and their associated ecology and systematics. Ph.D. thesis, University of British Columbia, Vancouver, British Columbia, Canada.

Harvey, B., and T. Brown. 2011. Recovery potential assessment for the Umatilla Dace (Rhinichthys umatilla). Canadian Science Advisory Secretariat research document 2011/ 107. Fisheries and Oceans Canada, Ottawa, Ontario, Canada.

Kaya, C. M. 1991. Laboratory spawning and rearing of Speckled Dace. Progressive Fish Culturalist 53: 259-260.

Keeler, R., L. Porto, and C. Lawrence. 2010. Lower Columbia River sculpin and dace life history assessment (CLBMON-43): literature review. AMEC Earth \& Environmental, Nelson, British Columbia, Canada. Accessed 7 December 2015. http://tinyurl.com/jojn541.

McPhail, J. D. 2007. The Freshwater Fishes of British Columbia. University of Alberta Press, Edmonton, Alberta, Canada.

Murphy, B. R., and D. W. Willis. 1996. Fisheries Techniques. Second edition. American Fisheries Society, Bethesda, Maryland, USA.

Peden, A. E. 1991. Status of the Leopard Dace, Rhinichthys falcatus, in Canada. Canadian Field-Naturalist 105: 179188. 
Peden, A. E., and G. W. Hughes. 1981. Life history notes relevant to the Canadian status of the speckled dace (Rhinichthys osculus). Syesis 14: 21-31.

Peden, A. E., and G. W. Hughes. 1984. Status of the Speckled Dace, Rhinichthys osculus, in Canada. Canadian FieldNaturalist 98: 98-103.

Peden, A. E., and G. W. Hughes. 1988. Sympatry in four species of Rhinichthys (Pisces), including the first documented occurrences of $R$. umatilla in the Canadian drainages of the Columbia River. Canadian Journal of Zoology 66: $1846-1856$.
Peden A. E., and S. Orchard. 1993. Vulnerable dace populations of the Similkameen River 1992-1993, interim report. Habitat Conservation Fund, Victoria, British Columbia, Canada.

Ricker, W. E. 1971. Methods for Assessment of Fish Production in Fresh Waters. Second edition. Blackwell Scientific Publications, Oxford, United Kingdom.

SARA Registry. 2016. Species profile, Umatilla Dace. Accessed 2 September 2016. http://sararegistry.gc.ca/species /speciesDetails_e.cfm?sid=121\#ot 18 .

Received 14 December 2015

Accepted 21 April 2016 